\title{
Midiatização, crise da enunciação jornalística e a multiplicidade de enunciadores
}

\author{
Viviane Borelli
}

\section{Introdução}

M esmo que os jornais ainda tentem controlar o processo produtivo - no modelo clássico de transmissão de informação de um emissor para um receptor, fazendo projeções de quem seria o seu leitor - os discursos acabam seguindo rumos não previstos: notícias são compartilhadas e comentadas por leitores nos sites de redes sociais (Recuero, 2009) numa ampla cadeia significante. Isso denota que o processo de enunciação não ocorre de forma linear, pois há ressignificações e conexões mais amplas e difusas. Ou seja, não é só o jornalismo que dá inteligibilidade social aos fatos, mas por meio de interações e construções próprias os leitores também dão sentido ao mundo que os cerca.

Nesse contexto, o jornalismo vive uma certa 'crise de identidade' e de performance, pois não guarda mais para si nem a autonomia e nem a competência para a geração de conteúdo informativo. Como problematiza Fausto Neto (2012: 62), "o jornalista não é o mestre principal da sua atividade discursiva, uma vez que seu ato se encontra no meio de uma rede de interdiscursos, de fluxos de meios e de produções de coenunciadores (...). Deixa de ser o mediador clássico”.

Compreende-se que as relações entre jornais e leitores ocorrem de forma distinta entre os que possuem ampla circulação nacional - os de referência - e os regionais. Nosso olhar volta-se para os jornais de circulação mais 'comunitária', para compreender em que medida esses periódicos são afetados mais recentemente pelo processo de midiatização da sociedade. Diferentemente de jornais de circulação nacional, que começaram a fazer experimentações há quase duas décadas no que se 
refere ao contato com o leitor através do ambiente digital, esses periódicos começaram mais recentemente a desenvolver estratégias para interagir com seus leitores e alguns, inclusive, ainda o fazem de forma muito inicial.

Os jornais do interior gaúcho - Diário de Santa Maria, Pioneiro, Gazeta do Sul, A Plateia, O Nacional, A Razão e Diário Popular - também são afetados pelo processo de midiatização em distintos estágios. Os sete jornais são objeto de estudo há quatro anos por meio da pesquisa "Produção e circulação da notícia: as interações entre jornais e leitores". ${ }^{1}$ A escolha dos jornais deve-se às diferentes épocas em que foram criados, aos modos através dos quais cada um deles busca contatar o seu leitor, pela circulação que tem nas regiões que abrangem e pelo acesso aos dados. Os quatro últimos foram criados antes dos anos 40 do século passado e são centenários.

Diante da cultura da convergência (Jenkins, 2009), há transformações nas relações entre produtores e receptores, o que implica na construção de novas regras e estratégias de contato entre eles. Nesse sentido, se outrora havia como precisar quem era o leitor dos jornais mais comunitários e que circulam em áreas geográficas específicas, hoje já não é mais possível diante da circulação de informações no ambiente digital. Mesmo assim, os jornais analisados continuam construindo um contrato de leitura (Verón, 2005) que visa estabelecer uma relação de proximidade com o leitor 'local', já que para esses jornais a edição impressa ainda é o centro de sua atividade e os temas abordados são predominantemente relativos à cidade-sede. Entretanto, esse contrato é elaborado a partir de uma projeção, o que implica em possíveis outros caminhos tanto interpretativos quanto do ponto de vista da circulação.

Notou-se que os jornais ofertam dispositivos através dos quais o leitor pode interagir com ele, entretanto, num dado momento a interação deixa de ser controlada pelo jornal e segue rumos próprios. Isso ocorre principalmente através de notícias postadas nos portais ou sites oficiais que são rapidamente compartilhadas e comentadas por leitores nos sites de redes sociais. O jornal é interpelado pelo leitor nas redes sociais, mas geralmente silencia, o que demonstra que o processo de enunciação é marcado por múltiplas interpretações possíveis, por complementaridades, mas também por vazios. Percebeu-se que a questão do acesso dos leitores dos jornais está, de certa forma, sedimentada, porém há questionamentos em dois âmbitos principais: como os leitores ressignificam essas notícias e, do ponto de vista da produção, como os jornais têm lidado com esses coprodutores.

Dessa maneira, constatou-se a necessidade de uma nova etapa de investigação que analisasse a circulação da notícia, já que no projeto anterior foi investigada a instância da produção, especialmente as estratégias utilizadas pelos jornais para contatar o seu leitor. Nesse contexto, em outro artigo $^{2}$, deu-se continuidade à problemática de pesquisa anterior acerca dos processos interacionais entre jornal e leitor, ampliando-se o olhar para a problemática da circulação, especialmente a partir do 
mapeamento dos caminhos que a notícia segue - por meio da ação de seus leitores - para além do dispositivo jornal.

Nesse artigo visa-se investigar em que medida os jornais estão encarando essa emergência de novos produtores de conteúdo, ou seja, os jornais estão preparados para esse novo tipo de jornalismo que é produzido pelos leitores? Questiona-se ainda se há preocupação por parte dos jornais em compreender o trabalho interpretativo que é realizado pelos leitores. Para dar conta de responder essa questão, recorre-se a dados coletados nos últimos quatro anos por meio de entrevistas com jornalistas e editores dos jornais. Além disso, através de observação sistemática (Gil, 2006), nos portais e sites oficiais e nos sites de redes sociais dos jornais ${ }^{3}$, objetiva-se também observar como o processo de midiatização afeta a enunciação jornalística.

\section{Processo de enunciação na sociedade em midiatização}

Compreende-se que o processo de midiatização afeta as práticas sociais, como o jornalismo, fazendo com que os atores envolvidos desenvolvam estratégias para continuar tendo legitimidade junto ao tecido social (Verón, 2012). Estamos diante de uma era em que as interações são afetadas e reconfiguradas por outras estratégias e modos de organização que colocam "produtores e consumidores - em uma mesma realidade, aquela de fluxos e que permitiria conhecer e reconhecer ao mesmo tempo". (Fausto Neto, 2008: 93).

É nessa ambiência do processo de midiatização da sociedade que pensamos a prática jornalística, que não sofre apenas mudanças em função do desenvolvimento de novas tecnologias ou de exigências cada vez mais duras do mercado de trabalho, mas sobretudo é afetada por outras lógicas de contato que são acionadas pelos seus usuários/receptores/consumidores/leitores. Novos contratos são construídos entre essas instâncias, novos regramentos são criados e também outras estratégias são desenvolvidas para que o contato seja alargado.

A noção de contrato é compreendida como uma metáfora para designar o vínculo entre quem produz e quem interpreta o texto. Para Boutaud e Verón (2007: 4), "a estabilidade dessa relação implica a dimensão da confiança no tempo, e as expectativas que concernem às características do produto discursivo em questão". É o dispositivo técnico e simbólico que dá forma aos contratos produzidos no âmbito da produção com objetivo de atingir seus leitores. Portanto, são os dispositivos que garantem as múltiplas interações entre o jornal e seus leitores através de processos de interação.

Em relação ao caso aqui abordado, nota-se que os jornais constroem discursos específicos e criam modos singulares para manter o vínculo com o leitor, projetando possibilidades de retorno por parte dos receptores para que cada vez mais o contato seja alargado. Dessa forma, "um mesmo emissor poderá construir enunciadores diferentes, conforme o alvo visado; pelo mesmo motivo construirá, cada vez dife- 
rentemente, seu destinatário". (Verón, 2005: 218). A construção de uma matéria com base em distintas fontes, a tematização de um grande rol de fatos que mereçam ter destaque noticioso visa atingir um amplo número de leitores, por exemplo.

Partindo da ideia de Pinto (2002: 67), de que "no interior de todo texto um enunciador se define, definindo igualmente um coenunciador (ou destinatário), definição que se faz pelo emprego seletivo de determinadas operações de enunciação", observa-se que os jornais buscam atingir determinados leitores, predefinindo quem poderiam ser eles. Isso ocorre por meio de operações que abrangem o tipo de notícia, o tema principal da matéria, a editoria em que é veiculada, o horário da postagem, as fontes utilizadas, a construção do próprio discurso da notícia (didática, científica...).

Entretanto, não há garantias de que isso ocorra, visto que todo discurso pode desenhar um campo possível de efeitos de sentidos e "não um e único efeito" (Verón, 2005: 216), pois a singularidade do discurso, o ambiente em que circula e o contexto em que se concretizam as relações entre produção e recepção podem levar a outros caminhos interpretativos, numa infinita cadeia de semioses.

Rodrigues (1994: 145) também problematiza as relações de interlocução e interação, afirmando que é necessário dar conta da enunciação para compreender os sentidos construídos, pois esse processo "atravessa o conjunto dos enunciados e que, ao mesmo tempo, institui, vigia e sanciona o seu sentido". O autor reflete sobre a constituição do dispositivo da enunciação a partir da ideia de que há outros valores de natureza contextual que servem de quadro de sentido ao enunciado. $\mathrm{Ou}$ seja, há algo muito além do significado dos enunciados proferidos e que faz parte dos quadros do sentido da enunciação. A partir desse raciocínio, as relações entre enunciado e enunciação caracterizam-se como um processo de ajustes no qual há "encaixes e desencaixes".

Com a emergência de outros enunciadores, que desconstroem a noção clássica de mediação do jornalista, é preciso problematizar a prática jornalística a partir da ideia de que cada vez mais há coenunciadores e não mais a relação clássica: enunciador/jornal e destinatário/leitor. Nesse contexto, o próprio conceito de contrato de leitura deve ser revisto a partir do pressuposto de que a circulação dissolve discursos construídos com um fim específico e também aciona discursos não previstos e não planejados.

Essas mudanças que dizem respeito ao modo como se diz, ou seja, ao processo de enunciação, fazem com que tenhamos outra leitura do que venhamos a construir como um dispositivo de enunciação ou quadro de sentido (Rodrigues, 1994). Se a moldura ou aquilo que é da ordem das determinações contextuais servem de quadro ao sentido do enunciado, devemos considerar que se outrora esse dito vinha hierarquicamente do sistema midiático atualmente há outros enunciadores nesse processo. A emergência dessas falas remete a construções de outros quadros de sentido, pois aquilo que é da ordem contextual molda o próprio sentido.

Nota-se que os leitores assumem um papel de coenunciadores dizendo como as matérias devem ser escritas. Um dos preceitos do jornalismo é justamente o fato 
de que os jornalistas têm o papel de falar sobre o presente por meio de avaliações que tomam como base critérios de noticiabilidade, em que o discurso jornalístico deve basear-se num caráter referencial. Entretanto, essa especificidade do trabalho jornalístico é permeada pela interferência e ingerência sobre o dito que vêm de outro sistema que não o midiático, mas sim do sistema leitores.

Como pressupõe Luhmann (2005: 30), os temas são uma necessidade da qual os meios de comunicação não podem abrir mão, pois eles "representam a heterorreferência da comunicação" e também são eles que garantem o acoplamento estrutural com outras áreas da sociedade. Entretanto, quando o sistema midiático não produz temas que dialoguem e satisfaçam os anseios de seus leitores não há acoplamentos, mas sim irritações e divergências, gerando descontentamentos que podem vir em forma de sugestão, crítica, comentário, como apontam os enunciados postados na fanpage do jornal Pioneiro.

Para ter maior alcance em suas publicações, a abertura para os leitores é primordial na concepção de Domingo (2011), pois se torna uma garantia de mais participação. Através da motivação para um maior engajamento dos leitores será possível, para o autor, incentivar mais retornos de qualidade. O autor também ressalta que não bastam abrir portões para a participação dos leitores, pois é necessário "achar estratégias apropriadas e definir novas práticas para lidar com as contribuições dos usuários"4 (Domingo, 2011: 77, tradução própria).

Ao mesmo tempo em que o jornal enuncia amplamente que o leitor é um coenunciador, ele estabelece as regras para essa "participação". O jornal amplia o processo de enunciação da realidade, possibilitando que os leitores o ajudem a construir o presente, entretanto ele regula esse processo, determinando os regramentos. Ou seja, mesmo que ele se apresente como um sistema aberto, ele o fecha quando lhe convém e julga ser necessário enclausurar-se, ocorrendo um fechamento operacional do sistema (Luhmann, 2005).

Esse regramento por parte do sistema midiático repercute no sistema leitores, que interpretam a imposição sobre autoria e responsabilidade sobre o que é dito no âmbito institucional de distintas formas. Um caso interessante é o da Gazeta do Sul, que a exemplo de outros jornais, deixa claro tanto no site quanto na fanpage as regras para comentários (Figura 4). Alguns leitores concordam com os regramentos, debatendo a responsabilidade sobre o que pode ser dito: "O que o povo pensa deve ser divulgado". "Está certo. Quem opina tem que ser responsável". Porém, outros desaprovam: "não curti isso" e ainda há os que questionam o funcionamento e a dinâmica do próprio processo interacional: "Só publicam os comentários convenientes..os outros são deletados".

Os leitores produzem interpretações próprias sobre o processo de interação que é possibilitado pelo sistema, ora aberto e ora fechado, que dita as regras e é o maestro do processo interacional. Nesse sentido, vale lembrar a analogia da or- 
questra para explicar o conceito e o processo de comunicação para a Escola de Palo Alto. Mesmo que aparentemente o sistema midiático denote que todos possam participar, colaborar com seus ditos para a produção jornalística e ser efetivamente enunciadores da realidade, as regras, limites e restrições para tal fazem com que esse processo seja regulado.

\section{Leitores em interação}

A partir da problemática atual de cambio de lugares acerca de quem enuncia para quem, não há como precisar quem é o leitor/consumidor/usuário/receptor. Do ponto de vista da Linguística, todo autor elabora o seu discurso a partir da projeção de possíveis leitores, em que ao organizar determinada estratégia textual configuram-se certas competências que possam fazer sentido ao que é dito. Essa concepção é a de um leitor-modelo (Eco, 1986) em que se projeta a imagem de um possível e potencial leitor, fazendo com que o discurso seja produzido a partir de certas prescrições.

Nesse sentido, é preciso lembrar que a todo autor empírico "corresponde o seu público ou audiência (ouvintes, leitores, espectadores, etc.), que são os indivíduos de carne e osso a quem caberá interpretar o texto produzido" (Pinto, 2002: 35). No caso dos grandes jornais, pesquisas quantitativas e de sondagem de opinião podem dar dados mais precisos de quem é o leitor dos periódicos. Mas, no caso dos jornais de menor circulação, mesmo com algumas pesquisas realizadas pelo setor de circulação ou comercial, que indicam características socioeconômicas de assinantes, cabe, via de regra, à Redação projetar a imagem de quem seriam seus leitores.

Como já ressaltado, na cultura da convergência e com o processo de circulação da informação, hoje é difícil precisar quem é o leitor empírico, pois estamos diante de uma ampla tipologia de públicos. Entretanto, a instância da produção faz a projeção de quem é esse leitor construído por meio do discurso. Por outro lado, mesmo com a dificuldade de definir e de precisar quem é o leitor, os jornais estão diante de pistas muito ricas sobre as lógicas de interação que mobilizam os leitores a contatá-los e que sentidos são construídos pelos leitores nesse processo interacional.

Os editores dos jornais foram entrevistados duas vezes nos dois últimos anos (2011 a 2015) e têm opiniões diversas sobre quem seriam seus leitores ideais/ modelos/almejados. No Diário de Santa Maria, o contato com os leitores encontra-se em mutação: "agora o público nos mantém informado das coisas, a gente pega

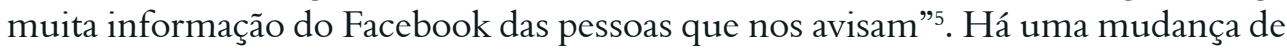
percepção do que é notícia a partir da entrada em cena de outros enunciadores que não apenas os jornalistas, havendo, uma troca de papéis: outrora quem informava era o jornal, mas hoje os usuários do Facebook são coprodutores.

O jornal faz adequações em sua enunciação de acordo com mudanças percebidas nas características de seus leitores. A editora-chefe da Gazeta do Sul explica 
que o jornal era concebido prioritariamente para uma comunidade germânica, o que mudou nos últimos anos: "Antigamente, dizia assim uma matéria: "Santa Cruz, uma cidade colonizada por alemães. Isso é proibido agora"6.

O leitor de carne e osso passa a ser estrategicamente estudado pelo jornal para além da projeção daquele que seria um leitor ideal. Para o chefe de reportagem da Gazeta do Sul, o ambiente digital possibilita um melhor conhecimento para quem se produz conteúdo, ou seja, o leitor empírico: "Ao mesmo tempo em que a gente acata sugestões do leitor, a gente vê o que está interessando o leitor e o caso do portal é interessante porque ele também te dá um feedback que no impresso tu não tem" . O jornalista acrescenta que o periódico registra uma boa participação por meio de e-mail e telefone, o que denota que o contato dos leitores com o jornal de abrangência regional não é predominantemente pelo portal ou Facebook: "temos um espaço na página 2, o Fale com a Gazeta, com o telefone de todos os editores e mails e quando sai tem um retorno interessante".

\section{Sistemas em relação}

$\mathrm{Na}$ cadeia interacional, nota-se que quando o jornal enuncia algo sobre a realidade e é questionado, não responde de forma direta às interpelações dos leitores, silenciando naquele momento específico. Desse modo, o processo interacional e a relação entre os interlocutores podem não se concretizar nesse contexto particular, mas poderão ser construídos outros quadros de sentido em momento posterior.

Isso ocorre, por exemplo, quando alguns temas que são gerados em outros sistemas acabam sendo incorporados pelo sistema midiático, que os transforma através de outro processo de enunciação. Por meio de acoplamentos de temas, processos heterorreferenciais e autorreferenciais (Luhmann, 2005), em que a comunicação ocorre de forma assimétrica, os jornais acabam transformando em seus próprios temas o que vem do sistema leitores. A partir disso, o ponto de partida para a comunicação de um fato não é mais proveniente apenas da mídia, mas também daquilo que os leitores pensam, almejam e intencionam colocar 'na rede'.

Nessa direção, foi observado no Diário Popular que um leitor sugere ao jornal que os homicídios sejam contabilizados, o que o periódico faz no dia seguinte, no início da notícia sobre mais uma morte. A partir dessa ação, o sistema midiático passa a produzir irritações (Luhmann, 2005) que são transformadas em informações para a sociedade.

Sobre a participação dos leitores no fazer jornalístico, editores avaliam que com a Internet ela se intensificou, especialmente através das redes sociais, mas admitem que não há como dar conta de tamanha profusão de opiniões e comentários. O "Facebook é um canal muito interessante para a interação, mas isso é o obvio, mas os jornais lidam mal com isso. A gente não responde a tudo que vem do Facebook, não 
dá porque o nosso fluxo é muito grande ali... a gente responde o que é relevante"

O excesso de participação por parte dos leitores também é problematizado a partir da concepção de que o jornal não consegue abarcar tudo o que vem da instância da recepção, mesmo que ali seja o lócus onde mais ocorre esse contato: "A interação imediata do leitor se dá nas redes sociais. Ou pelos comentários do nosso site. Tá sempre, assim... Tem muito, sabe. Todo mundo quer comentar tudo. Então tem muito" ${ }^{10}$. A estrutura dos jornais menores também interfere na relação com os leitores, pois a demanda torna-se grande: "Dá mais trabalho, chega mais material, então às vezes tu tem lista de espera porque tu não tem perna para atender toda demanda, mas é bom porque tu sempre tem pauta, tu não chega numa situação de dizer "pô, não tenho o que fazer, não tenho pauta"" 1 .

A enquete ainda é um recurso utilizado pelos jornais para transformar temas comentados por leitores nas redes sociais em matéria-prima. A enquete foi um dos primeiros movimentos criados pelos jornais, ainda na materialidade do impresso, para instigar o leitor contatá-lo. Antes, o tema era lançado num dia e as respostas eram publicadas no dia seguinte a partir da participação por e-mail. Hoje, os jornais criam enquetes em seus sites e fanpages de forma integrada, mas ainda publicam o resultado na edição impressa, havendo conexões entre os dispositivos.

Diante das interações entre os sistemas midiático e dos leitores, os fluxos ocorrem em várias direções. Exemplo é a elaboração de reportagem especial feita por A Plateia sobre um assunto que teve repercussão nas redes sociais, que havia sido tema de uma enquete e que o jornal havia constatado que fora uma das que mais teve participação de leitores. O jornal pede aos leitores que participem da construção de reportagem por meio de respostas à enquete (dia 21 de maio) e depois publica a matéria (dia 24 de maio) enunciando que o tema foi produzido pelos leitores: "O preconceito contado pelos santanenses". Nesse sentido, a cadeia produtiva que une esses diferentes sistemas é infinita, segue caminhos não previstos e o processo de enunciação não é linear.

O vínculo entre jornais e leitores não ocorre apenas através das redes sociais, pois nota-se que algumas promoções mais pontuais que envolvam a comunidade representam a construção de laços identitários fortes entre eles. Exemplos são festas tradicionais organizadas pelo sistema midiático que se vale de processos técnicos e discursivos para difundir esses valores, como a festa do Dia do Vizinho - Jornal A Razão, que acontece todo o ano em Santa Maria, e o Festival do Folclore - O Nacional, que ocorre em Passo Fundo. 


\section{Considerações}

São diversas as pesquisas que hoje refletem sobre o fazer jornalístico diante do avanço tecnológico, da expansão da cultura da convergência, das mutações nos processos comunicacionais. Nesse sentido, busca-se investigar essas mudanças a partir dos conceitos de midiatização, enunciação e sistema. O artigo integra uma problemática mais ampla que visa refletir também sobre o futuro do jornalismo diante desse contexto.

O jornal não responde de forma direta às interpelações dos leitores, mas acaba trazendo para sua produção noticiosa temas que são gerados pelos leitores e que têm ressonâncias, especialmente, nas redes sociais. Essa é uma estratégia utilizada para mostrar aos leitores que eles estão presentes e integram o fazer jornalístico. Esse contrato visa a manutenção do vínculo e o alargamento do contato para além da materialidade do impresso.

Cada jornal age de forma singular ante o momento de incerteza vivenciado pelo jornalismo: alguns fazem uso de temas que circulam nas redes sociais para transformar em insumos para suas notícias; outros ainda estão presentes nas redes sociais de forma figurativa e alguns fazem experimentações que buscam aproximar, manter e ampliar o contato com seus leitores.

Compreende-se que o contato entre jornal e leitor só se concretiza através de processos de enunciação. Nesse sentido, os fluxos gerados pelas enunciações decorrem da proposição de um contrato de leitura, mas as gramáticas de reconhecimento levam a outros caminhos e trajetos não previstos pela produção (Boutaud e Verón, 2007).

Estamos diante de uma era de incertezas, em que os quadros de sentido outrora construídos pelos jornais como uma moldura aos seus enunciados agora tomam forma por processos de enunciação atravessados por outros sistemas. A mídia não detém mais o privilégio de controlar a mediação, pois o processo de midiatização da sociedade põe em cena outros atores e discursos.

Nesse sentido, a mediação jornalística é colocada em suspensão, são questionados seus preceitos acerca do que é notícia, são sugeridos outros olhares da sociedade e novas construções sobre os temas gerados. A era é de incertezas, mas hoje o processo de circulação nos proporciona indicadores e marcas muito vivas da presença e do anseio de leitores acerca do sistema midiático. O desafio é mapear essas interações e compreender esses processos de enunciação para além do que aparentam, pois não são dados prontos e encontram-se numa cadeia infinita de sentidos.

Viviane Borelli

Professora da Universidade Federal de Santa Maria (UFSM) 
Recebido em agosto de 2015.

Aceito em abril de 2016.

\section{Notas}

1. A pesquisa é realizada com apoio financeiro do Conselho Nacional de Desenvolvimento Científico e Tecnológico, por meio da Chamada 43/2013 - Ciências Humanas, Sociais e Sociais Aplicadas.

2. BORELLI, Viviane. A circulação da notícia na sociedade em processo de midiatização: o caso de jornais de abrangência regional. Revista Rizoma vol. 3 n . 1 (2015).

3. Para a coleta de dados, realizada em 2014 e 2015, contou-se com a colaboração dos alunos de Iniciação Científica dos cursos de Comunicação - Jornalismo da UFSM: Laura Moura de Quadros, Luan Moraes Romero e Gabriele Wagner de Souza; e do mestrado em Comunicação, Francieli Jordão Fantoni e Marlon Santa Maria Dias. Por compreender que os dados estão numa rede social e que são, portanto, públicos, optou-se por não esconder a identidade dos leitores que deixam comentários nas páginas dos jornais.

4. Original: "to find an appropriate strategy and define a new set of practices for handling these user contributions".

5. Da editora-chefe do Diário de Santa Maria, Andreia Fontana, em entrevista concedida em 24 de setembro de 2014, na sede do jornal, em Santa Maria.

6. Da editora-chefe da Gazeta do Sul, Maria Rosilane Zoch Romero, em entrevista concedida em 26 de junho de 2012, na sede do jornal, em Santa Cruz do Sul.

7. Do chefe de reportagem da Gazeta do Sul, Ricardo Düren, em entrevista concedida em 26 de junho de 2012, na sede do jornal, em Santa Cruz do Sul.

8. Do chefe de reportagem da Gazeta do Sul, Ricardo Düren, em entrevista concedida em 6 de novembro de 2014, na sede do jornal, em Santa Cruz do Sul.

9. Do editor-chefe do Diário Popular, Pablo Rodrigues, em entrevista concedida em 10 fevereiro de 2015, na sede do jornal, em Pelotas.

10. Da editora-chefe do O Nacional, Zulmara Colussi, em entrevista concedida em 20 de agosto de 2012, na sede do jornal, em Passo Fundo.

11. Do chefe de reportagem da Gazeta do Sul, Ricardo Düren, em entrevista concedida em 26 de junho de 2012, na sede do jornal, em Santa Cruz do Sul. 


\section{Referências}

BOUTAUD, Jean-Jacques e VERÓN, Eliseo. Del sujeto a los actores. La semiótica abierta lãs interfaces. In: Sémiotique ouverte. Itinéraires sémiotiques en communication. Paris: Lavoisier, Hermes Science, 2007. Texto avulso.

DOMINGO, David. Managing Audience Participation: Practices, workflows and strategies. In: SINGER, Jane B. et al. Participatory Journalism: Guarding Open Gates at Online Newspapers. [s.i]: Wiley-blackwell, 2011. Cap. 5. p. 76-95.

ECO, Umberto. Leitura do texto literário: lector in fabula. Lisboa: Presença, 1986.

FAUSTO NETO, Antonio. Narratividades jornalísticas no ambiente da circulação. In: SOSTER, Demétrio e PICCININ, Fabiana. Narrativas comunicacionais complexificadas. Santa Cruz do Sul: Edunisc, 2012.

FAUSTO NETO, Antonio. Fragmentos de uma "analítica" da midiatização. Revista Matrizes. São Paulo: ECA/USP, ano 1, no 1, 2008, pp. 89-105. Disponível em: http://www.usp. $\mathrm{br} /$ matrizes/img/02/Dossie5_fau.pdf. Acesso em: 11/07/2013.

GIL, Antonio Carlos. Métodos e técnicas de pesquisa social. São Paulo: Atlas, 2006.

JENKINS, Henry. Cultura da Convergência. São Paulo: Aleph, 2009.

LUHMANN, Niklas. A realidade dos meios de comunicação. São Paulo: Paulus, 2005.

PINTO, Milton José. Comunicação e discurso: introdução à análise de discursos. São Paulo: Hacker Editores, 2002.

RODRIGUES, Adriano Duarte. Dispositivo da enunciação. In: RODRIGUES, A. D. Comunicação e cultura: a experiência cultural na era da informação. Portugal: Editorial Presença, 1994. VERÓN, Eliseo. Fragmentos de um tecido. São Leopoldo: Unisinos, 2004.

VERÓN, Eliseo. Midiatização, novos regimes de significação, novas práticas analíticas? In: FERREIRA, M. F.; SAMPAIO, A. O.; FAUSTO NETO, A.(orgs). Mídia, Discurso e Sentido. Salvador: EDUFBA, 2012. 


\title{
Resumo
}

Os jornais desenvolvem estratégias para adequar-se à ambiência da midiatização, mas, muitas vezes, demonstram não saber que caminho tomar diante da protagonização do leitor, do predomínio de material noticioso que circula nas redes sociais e do atravessamento de múltiplas enunciações. O objetivo do artigo é mostrar operações que indiquem como o processo de enunciação jornalística é afetado pela midiatização. Para isso, fez-se entrevistas com editores para compreender como as enunciações dos leitores são problematizadas e transformadas no fazer jornalístico. Foram coletados materiais noticiosos publicados por sete jornais do interior gaúcho. Além disso, analisaram-se marcas discursivas deixadas por leitores no ambiente digital que apontem para a emergência de outras enunciações além da jornalística.

\section{Palavras-chave}

Midiatização. Jornalismo. Enunciação.

\begin{abstract}
The newspapers develop strategies to adapt to the ambience of mediatization, but often demonstrate not to know which way to assume in face of protagonism of the reader, the predominance of news material that circulates on social networks and crossing of multiple enunciations. The aim of the article is to show operations that indicate as mediatization affects the process of journalistic enunciation. For this, it was made interviews with editors to understand as enunciations of the readers are problematized and transformed in newsmaking. News materials published by seven newspapers of the gaucho inside were collected. Furthermore, were analyzed discursive marks left by readers in the digital environment which point to the emergence of other enunciations beyond journalistic enunciation.
\end{abstract}

\section{Keywords}

Mediatization. Journalism. Enunciation. 